\section{UM SÉCULO DE \\ BIBLIOGRAFIA LUCIÂNICA: A HISTÓRIA DE UMA POLÊMICA}

tável quanto, de outro, o silêncio da crítica. Os scholars, em geral, utilizaram o corpus lucianeum mais como uma espécie de enciclopédia que registra dados preciosos mas pontuais, cobrindo interesses que vão da crítica das artes plásticas à história da medicina, dos primórdios do cristianismo à teorização da história, etc. Estudos sobre o corpus lucianeum em si são contudo escassos, considerada sua importância documental e, sobretudo, sua importância literária. Basta passar os olhos pelos títulos registrados em L'Année Philologique, comparando-se a bibliografia crítica sobre Luciano com aquela dedicada a outros "grandes" escritores antigos, como Homero, os trágicos, Heródoto, Tucídides, Platão, etc.

Não é minha intenção aqui fazer nem a história da recepção literária de Luciano $^{4}$, nem a história dos usos e abusos de sua obra como fonte de informação $^{5}$, mas apenas esboçar um balanço da bibliografia crítica sobre o corpus lucianeum, desde a publicação dos livros de Bernays e de Croiset, em 1879 e 1882 respectivamente, tendo em vista, sobretudo, a produção de nosso século, isto é, de que modo, nos últimos cem anos, se formou e se desdobrou o que Reardon batizou como a "questão luciânica" (Cf. Reardon, 1971, p.160). Trata-se, sem dúvida, da história de uma polêmica em torno do sentido ou dos sentidos da produção de Luciano. No conjunto, pode-se dizer que não há pontos consensuais, como os estabelecidos em nosso século a respeito de outros corpora igualmente difíceis e importantes, como os poemas homéricos, os trágicos, Platão e Hesíodo, entre outros. De um certo modo, perpetua-se o mesmo desconforto já registrado pela Suda, por Fócio ou pelos inúmeros escoliastas que anotaram, à margem dos manuscritos, a expressão de sua admiração e indignação. A questâo luciânica -- de que aqui tomarei os representantes mais destaca- 
dos, isto é, os críticos que propuseram teorias gerais sobre o sentido do corpus lucianeum - essa polêmica, no fundo, decorre do próprio Luciano, alguém de quem, nas palavras de Fócio, só se pode dizer que tem como crença "em nada crer"6. Alguém, portanto, que induz não ao consenso, mas à polêmica.

Jones afirma, na introdução de seu livro, intitulada precisamente "The Modern Lucian", que "the criticism of Lucian is an involving phenomenon, and that Lucian's observer is as much subject to the past as he was" (Jones, 1986, p.1). $\mathrm{O}$ mesmo Jones regride a história da crítica moderna sobre Luciano a 1879 , quando aparece o livro de Jacob Bernays, Lucian und die Kyniker, de que dependem os desdobramentos das teses de Rudolf Helm, apresentadas em "Lukian und die Philosophensschule" (Helm, 1902) e, principalmente, em Lukian und Menipp (Helm, 1906). Partindo de Bernays, bem como de comentários esporádicos de Wilamowitz e Norden, e empenhado no método da Quellenforschung, Helm radicaliza a declaração luciânica de que, para a criação do diálogo cômico, desenterrara o "velho cão Menipo" (Dupla acusação, 33); assim, defende que o diálogo luciânico nada mais seria que a retomada da sátira menipéia, de tal modo que seria possível reconstituir esta última através da análise criteriosa daquele. Em Lukian und Menipp, Helm põe justamente em prática sua teoria, que terá grande influência sobre a crítica posterior, pelo menos até o período entre as duas guerras. Embora sua análise de aspectos pontuais de diferentes textos tenha inegável importância, sua postura teórica peca pelo viés de supor que a obra de Luciano tem valor apenas relativo, na medida em que não constrói um sentido próprio, ficando na esfera do pastiche e da mera imitação.

A tese de Helm, embora rebatida ainda na primeira metade do século (cf.
McCarthy, 1934), terá grande difusão. Nos meios não especializados, ainda é lugar comum considerar Luciano autor de sátiras menipéias, o que se deve em parte, à obra de Bakhtin (Bakhtin, 1963) que, se de um lado recupera a produção luciânica, localizando-a, junto com o diálogo "socrático", como uma das fontes da literatura carnavalizada, por outro lado toma-a apenas, tout court, como um dos representantes do gênero inaugurado por Menipo ${ }^{7}$. Ora, o que McCarthy demonstra, no alentado artigo publicado em Yale Classical Studies, é que a afirmativa da Dupla acusação deve ser entendida no contexto das demais declarações do próprio Luciano sobre sua obra, as quais ressaltam a originalidade do projeto de mesclar o diálogo filosófico à comédia. De fato, não pode haver dúvida quanto a isso: em Zêuxis e, sobretudo, em Tu és um Prometeu em teus discursos, a novidade do diálogo luciânico é suficientemente res:saltada (Es Pr. 3-7). Nada autoriza considerar tais declaraçōes como embuste, em nome da dependência de modelos perdidos. É preciso levar em conta que Menipo, na mesma passagem da Dupla acusação, é citado apenas como uma das fontes que se mesclam para dar origem ao diálogo luciânico, ao lado do jambo, de Êupolis e Aristófanes, sobre a base de fundo que é constituída pelo diálogo filosófico - em especial, acredito, o platônico. Assim, a proposta de McCarthy (McCarthy, 1934, p.6) de que Luciano apenas finge depreciar o mérito da novidade para realçá-la pode também ser descartada, em favor de uma leitura mais acurada do próprio texto luciânico.

Enfim, o estado atual da questão da dependência menipéia é bem resumido por Coenen: 1 . Como observou McCarthy (McCarthy, 1934, p.20 ss), a sátira menipéia não era, pelo menos no que podemos saber, puro diálogo, mas geralmente preponderava nela o ele- 
mento narrativo, como de fato se constata em Icaromenipo e Neciomancia, os quais seriam os dois únicos exemplos do gênero no corpus lucianeum (também a Apocoloquintose de Sêneca e as menipéias de Varrão concordam com essa tendência narrativa); 2. "So dürfen wir Lukians Behauptung, dass er den Menipp 'in der Dialog einfuhrte' (Bis acc. 33), durchaus wortlich verstehen. Menipp war nicht sein ausschliessliches Vorbild, sondern er bot ihm satirische Stoffe, aus denen er unter Hinzunahme von Formen und Motiven aus der Komödie seine dramatischen Dialoge schuf" (Coenen, 1977, p.36-37).

O livro de Maurice Croiset, Essai sur la vie et les oeuvres de Lucien (Croiset, 1882), pode, como o de Helm, ser considerado o inaugurador de uma outra linha de abordagem que fará sucesso. Croiset procura avaliar a obra de Luciano de uma perspectiva diferente, concentrando-se sobre as qualidades de seu estilo, em detrimento dos conteúdos, pintando a figura de um escritor tão refinado quanto alheio ao mundo à sua volta, em cuja produção não descobre nenhuma unidade (cf. Croiset, 1899, p.598). Sua influência parece-me desdobrar-se em duas direçōes: de um lado, as pesquisas sobre a vida de Luciano ou melhor, o que se poderia depreender sobre isso dos textos do próprio Luciano; de outro, a abordagem do corpus lucianeum do ponto de vista da oposição entre imitação e criação, título, aliás, de um de seus capítulos. Tratarei separadamente dessas duas tendências.

A questão da biografia é das mais espinhosas. Antes de tudo, age o obstinado silêncio das fontes antigas, de que o exemplo mais contundente seria Filostrato ${ }^{8}$. Embora tratando da segunda sofística e dedicando-se ampla e detalhadamente a seus representantes mais ilustres, não se refere a Luciano. Isso significa que, ao contrário da crítica moderna, Filostrato não considera que Lu- ciano pertença ao movimento ou, no mínimo, indica que a produção luciânica é marginal nesse contexto. As concisas referências de Eunápio ${ }^{9}$, Lactâncio ${ }^{10}$ e Isidoro de Pelúsio ${ }^{11}$ não fornecem dados biográficos, a não ser a naturalidade de Samósata, a contemporaneidade com Demônax e a ligação com os cínicos. Ora, é bem provável que, da vida de Luciano, os três não conhecessem mais que nós mesmos, uma vez que a existência de Demônax é duvidosa (é razoável supor que ele seja apenas uma personagem luciânica) e a ligação com os cínicos é deduzida do próprio corpus lucianeum (e pode, nesse caso, estar baseada apenas no fato de Luciano ter escrito a própria Vida de Demônax). Das informações da Suda, acrescentamse os dados de que teria nascido na época de Trajano, iniciado sua carreira como advogado em Antioquia, dedicado-se em seguida à "logografia", morrido estraçalhado por cães e "herdado" o "fogo eterno" na companhia de Satanás! Como se vê, muito pouco, em que informações possivelmente autênticas (época do nascimento e início da carreira) se misturam com lendas e conclusões geradas pela apreciação crítica da obra.

Essa será grande tentação também para os biógrafos modernos, o que nāo deixa de ser compreensível, na medida em que vários textos do corpus lucianeum dão a impressão de ser autobiográficos, como Sobre um sonho (também chamado Vida de Luciano), Nigrino e outros. Gallavotti, em Luciano nella sua evoluzione artistica e spirituale (Gallavotti, 1932), parte do pressuposto de. que "la vita del nostro autore si legge tutta quanta nei suoi scritti velut in votiva tabella", bastando portanto ler adequadamente estes para reconstituir aquela (Gallavotti, 1932, p.1). Ele critica a obra de Croiset justamente por não ter intentado relacionar os escritos do corpus lucianeum com a biografia de seu 
autor, deixando de enfocá-lo em sua evolução como escritor e pensador. A proposta de Gallavotti lida assim com dois níveis de problemas de difícil solução: o mais básico, relativo à cronologia das obras; o mais geral, relativo à biografia propriamente dita. É desnecessário dizer que um depende do outro e, da perspectiva de umá evolução, a suposta biografia interfere no entendimento que se tem das obras. Nesse contexto é que a crença na conversāo de Luciano à filosofia, como retratada no Nigrino, ganhará importância. A conversão seria o marco antes do qual e depois do qual se organizariam as demais obras, correspondendo ao abandono da retórica. Essa tendência de organização cronológica do corpus lucianeum será amplamente seguida e, embora a suposta conversão tenha despertado muita polêmica, é tida como biográfica por grande parte dos comentadores, como Quacquarelli (Quacquarelli, 1956) e, mais recentemente, Jones (Jones, 1986). A questão é relevante, na medida em que resvala para outra polêmica: se Luciano teria sido filósofo, como já admitia Isidoro de Pelúsio e a crítica do século XVI, o que é ardorosamente negado por comentadores de diferentes épocas ${ }^{12}$.

O livro de Gallavotti agrupa-se ao lado de outros, anteriores e posteriores, em que a biografia, resvalando em cronologia, é o fio condutor, de que citaria como mais importantes os trabalhos de Hime, Lucian, the Syrian Satirist (Hime, 1900), e Allinson, Lucian satirist and artist (Allinson, 1926). A cronologia ganha o primeiro plano, de forma enriquecida e detalhada, no livro de Schwartz, Biographie de Lucien de Samosate (Schwartz, 1965). É interessante observar duas coisas: em primeiro lugar, que o aparecimento do livro foi precedido por um artigo sobre o problema da conversão à filosofia (Schwartz, 1964); em segundo lugar, que critérios como o da datação dessa mesma conversão - e outras miuçalhas do gênero que se possam depreender dos textos - não são o que de mais importante existe nele para o estabelecimento de uma cronologia relativa. $O$ que diferencia o trabalho de Schwartz do de outros é o estabelecimento de paralelos entre os escritos luciânicos e os de outros autores contemporâneos, permitindo avançar alguma coisa em seara tāo difícil. Ainda que se possa progredir pontualmente no conhecimento e na interpretação de vários aspectos -- ou mesmo discordar de pontos de vista defendidos por Schwartz - sua Biographie representa, em geral, no nível atual de conhecimentos, o que de mais seguro, objetivo e elaborado se pode ter sobre $o$ assunto.

$\mathrm{Na}$ linha da discussão sobre os processos de criaçāo e imitação, inaugurada com o livro de Croiset, o grande marco será o estudo de Bompaire, Lucien écrivain, imitation et création (Bompaire, 1958). Partindo da sugestão de Croiset e reorientando-a, através da desclassificação da oposição entre criação e imitação como processos antagô$\operatorname{nicos}^{13}$, Bompaire pretede estudar a "gênese" da obra, "voir, si possible, l'écrivain au travail, saisir la manière dont s'élabore l'oeuvre dans son esprit" (Bompaire, 1958, p.5). A imitação, na forma como a entendiam os antigos - e definida a partir de extensivo levantamento de fontes -- é tomada como método autêntico de criação, tanto na esfera do que se denomina, no livro, "criaçāo retórica", quanto na esfera da "criação literária". Essa postura metodológica situa o trabalho de Bompaire na vanguarda das correntes mais modernas de crítica, numa época em que ainda, com raras exceçōes, se repudiava a retórica em nome do ideal romântico da "originalidade". Se hoje, após toda a experiência da arte pós-moderna e das teorizações sobre a mesma, muitos dos pro- 
blemas com que o autor lida podem parecer-nos "sem problema", nos anos 50 certamente não seriam ${ }^{14}$. Declaradamente, ele confessa duas grandes influências: o livro de Helm, Lukian und Menipp, na qualidade de modelo da pesquisa sobre as fontes luciânicas; e Lucien et la pensée religieuse de son temps, de Caster (Caster, 1937), "qui au terme d'une étude philosophique et religieuse pose comme essentiel le probleme de l'écrivain' Lucien", o qual, declara ainda Bompaire, ele pretende defrontar (Bompaire, 1958, p.1). Ora, trata-se, nesse caso, de duas obras de orientação metodológica distinta: de um lado, a Quellenforschung; de outro, a pesquisa sobre as relações do corpus lucianeum com seu tempo. Num certo sentido, a polêmica em torno do livro de Bompaire deve-se à opção preferencial pela primeira tendência, com prejuízo da segunda abordagem.

No conjunto, Bompaire resgata de modo brilhante os processos poéticos de Luciano, livrando-os dos juízos de valor negativos, decorrentes de entendimento falho sobre a qualidade estética dos métodos de criação baseados na paródia, na citação, na remissāo - em suma, em todos os procedimentos situados na esfera da mimese de outras obras literárias, sem prejuízo da criatividade. De um lado, Bompaire situa a criação retórica, que supõe níveis diferenciados de utilização imediata de modelos, transmitidos sobretudo pela escola. Nāo há dúvida de que se trata de um processo poético de importância capital na Antigüidade, já que as referências se repetem em autores diferentes, como bem demonstrou Householder a propósito de Luciano, em comparação com outros escritores da segunda sofística (Householder, 1941). De outro lado, distingue ele a criação literária, em que "la Mimésis trouve son expression parfaite: l'assimilation profonde se substitue d̀ l'utilisation immédiate (...) et la place est libre pour une recréation du modele" (Bompaire, 1958, p.547). Em seu conjunto, Lucien écrivain pode ser considerado o mais completo estudo, ainda hoje não superado, sobre a poética de Luciano. Tem contudo o senāo de propor uma leitura totalizadora que, embora tenha a vantagem de desmontar a idéia de que falte ao corpus lucianeum qualquer unidade, acaba por perder muitos dos aspectos de uma obra rica e diversificada, na defesa de uma poética em que o escritor é basicamente devedor de sua biblioteca e não de seu tempo. Faltou a Bompaire, na verdade, dar o salto para a compreensão do sentido dos processos de criação, isto é, faltou-lhe problematizar os processos de recepção, tanto da perspectiva da recepção da literatura por Luciano, quanto da obra de Luciano por seu público.

As idéias e a metodologia de Bompaire serāo seguidas por um grande número de lucianistas, que se esmeraram em detalhar certos pontos sobre os processos miméticos, dentre os quais destacaria Anderson (Anderson, 1976[a], 1976[b], 1976[c], 1982) ${ }^{15}$, ou em aplicar a teoria da mimese para a compreensão não apenas do corpus lucianeum, mas para toda a segunda sofística, como faz Reardon (Reardon, 1971). Por outro lado, despertaram críticas, sobretudo da parte daqueles que defendem as imbricaçōes da obra luciânica com seu tempo, conjunto em que se destacam os livros de Baldwin (Baldwin, 1973) e Jones (Jones, 1986). Curiosamente, um antecessor desta última corrente pode ser encontrado no mesmo Caster que inspirou Bompaire. Outro, que considero da maior relevância, seria Peretti (Peretti, 1946).

O trabalho de Caster sobre Luciano e o pensamento religioso (e, por extensão, filosófico) de seu tempo teve, de um certo modo, o reconhecimento de sua importância prejudicado após a grande difusão, nas últimas décadas, das 
idéias de Bompaire, passando a ser lido apenas naquilo em que demonstra os "anacronismos". de Luciano, isto é, sua dívida para com os modelos clássicos. Isso, contudo, representa uma real redução de uma perspectiva mais ampla. $O$ livro foi publicado um ano antes de Etudes sur Alexandre ou le faux prophète de Lucien (Caster, 1938), em que o cuidado e senso arqueológico de buscar conexões entre o texto luciânico e seu tempo também se manifestam, neste caso movendo-se em terreno propício, uma vez que Caster trata de um opúsculo luciânico de caráter "jornalístico", sobre a atuação do conhecido profeta de Abonotico. Ora, o livro de 1937, embora voltado para um aspecto específico do corpus lucianeum, o das idéias religiosas, pode ser considerado uma obra de caráter abrangente, em vista da importância que têm a religião e a filosofia em Luciano. Caster passa, em detalhe, uma a uma, a caracterização luciânica das escolas de filosofia, definindo o nível de simpatia do escritor por cada uma delas. Em seguida, faz o mesmo com as correntes religiosas, situando a crítica de Luciano na esfera mais abrangente de crítica não a escolas ou correntes, mas à paidéia como um todo. Essa me parece uma contribuição essencial para o entendimento do sentido da obra de Luciano.

A mesma busca sistemática de conexōes contemporâneas frustra entretanto muitas vezes o autor, levando-o a cobrar de Luciano diversos "silêncios" e conduzindo-o à conclusão radical de que Luciano "vit au second siecle de notre ere avec l'esprit d'un contemporain de Ménandre; cinq cents ans de retard" (Caster, 1937, p.389). Nenhum desses silêncios logram todavia convencer-me da conclusão. Talvez tenha faltado a Caster uma concepção mais adequada de cultura e sociedade para a compreensão da crítica luciânica. Seria absurdo descartar a dívida de Luciano para com a tradição, mas é equivocado opor essa dívida à observação da realidade, uma vez que a realidade, para qualquer cultura, se institui no nível do imaginário em que a tradição é um dos fatores dinâmicos. Seria, por outro lado, prudente assumir uma atitude mais modesta, admitindo que não dispomos de todas as peças do quebra-cabeça das relações da obra luciânica com seu tempo. Um exemplo significativo milita a favor dessa hipótese: Caster considera uma obra central para a compreensão do pensamento religioso de Luciano, Assembléia dos deuses, nada mais que uma "phantaisie hâtive sans unité profonde" (Caster, 1937, p.345), "un document très vague pour l'histoire du second siècle", na medida em que o elemento principal da intriga (isto é, a discussão sobre os critérios para a concessão de cidadania aos deuses olímpicos) não remete diretamente à atualidade: "Quelle portée précise peut-on accorder à un ouvrage dont la donnée seule coïncide, à force de généralité, avec un fait d'histoire qui s'étend sur cinq siecles, tandis que les détails les plus frappants de l'actualité sont à peu près tous passés sous silence?" (Caster, 1937, p.342). Sua conclusão é assim taxativa: "A Assembléia dos deuses levanta, mais uma vez, de modo agudo, o problema das lacunas de Luciano" (Caster, 1937, p.346). Ora, na verdade, o desconcerto decorre antes de nossas lacunas, como demonstrou Oliver (Oliver, 1980), a partir da identificação de fragmentos epigráficos encontrados na ágora de Atenas como uma carta de Marco Aurélio relativa justamente à necessidade de comprovação da trigonia para os integrantes do Areópago. Ora, a cena luciânica no Olimpo não poderia deixar de ser, assim, mais atual. Isso demonstra, a contento, que as relaçōes do escritor com a sociedade podem dar-se não apenas sob a forma de referências jornalísticas diretas, mas, na esfera de sua competência ficcional, de modos 
muito mais ricos e variados, que podem nos parecer anacrônicos tão- somente porque sabemos pouco sobre essa mesma sociedade.

O livro de Peretti, Luciano, un intelletuale greco contro Roma (Peretti, 1946), embora, do mesmo modo que o de Caster, pareça interessado em uma abordagem parcial, concentrando-se quase que somente no estudo do Nigrino, toca questōes importantes para situar a produção luciânica. Em primeiro lugar, desmistifica a idéia de uma conversão à filosofia, definindo, creio que com absoluta precisão, o Nigrino não como um diálogo de conversão, mas como uma peça contra o Império. A conversão seria assim apenas o pretexto narrativo para o discurso de Nigrino, em que se tece o elogio de Atenas, pintada como cidade de filósofos, e o vitupério de Roma. Peretti coloca-se, desse modo, contra uma tendência geral de considerar-se Luciano ou como aliado ou, no mínimo, como alheio à questão do poderio universal romano, tendência essa que se estende de Hime (Hime, 1900, p.23) a Jones (Jones, 1986). Uma coisa acaba sendo certa: quem não concorda com a tese de Peretti não tem outra opção que admitir a veracidade biográfica da conversāo e, em decorrência, a própria existência histórica do filósofo Nigrino. Acredito, no entanto, que Peretti adota a posição mais correta, considerando-se o que há de sátira anti-romana também em Assalariados e a obstinada recusa de Luciano em representar personalidades romanas em seus textos. É incompreensível apenas que considere a Apologia como uma retrataçāo de Luciano, em termos de aceitação do Império, e não como simples defesa diante da acusação de capitulação, em que se expõe, para o destinatário do texto, que a investidura num posto da burocracia imperial, no Egito, se deveu apenas às necessidades impostas pela velhice.
A questão do interesse e do envolvimento de Luciano com os problemas não só políticos, mas também sociais de seu tempo tem marcado a cisão entre vários estudiosos, desde o aparecimento do artigo de Baldwin, "Lucian as Social Satirist" (Baldwin, 1961). Seu ponto de partida $E$ uma observação de pé-de-página de Rostovtzeff sobre a importância da questão social em Luciano (apud Baldwin, 1961, p.199), o que o leva a examinar o problema, enfocando textos como Neciomancia, os Diálogos dos mortos, Descida ao Hades, Fugitivos, Saturnálias e Sobre o sonho. Pinta-se assim a figura de um escritor interessado nas questōes sociais e inteirado de sua importância, não no plano de qualquer forma de ativismo, mas de reflexāo sobre o absurdo das disparidades de fortuna entre ricos e pobres. Essa figura é nuançada e, em certa medida, mitigada em Studies in Lucian (Baldwin, 1973), com a vantagem de ampliarse tanto o quadro dos interesses de Luciano pela sociedade de seu tempo, quanto os objetivos da crítica. Seja como for, os trabalhos de Baldwin tiveram a importância de pôr em questão as idéias de Bompaire, através da utilizaçāo de um marco teórico que recusa sua teoria da mimese, baseada na oposição entre observação direta da realidade e inspiração haurida na biblioteca. Ora, é evidente que se trata de um falso problema. Caso contrário, teríamos de admitir que um escritor efetivamente engajado, como Brecht, também seria anacrônico, uma vez que deve muito a sua biblioteca (inclusive a sua biblioteca grega). $O$ que Baldwin demonstra bem é como o uso da biblioteca por Luciano é regulado pela "realidade" cultural e humana para a qual escreve. Poderíamos avançar mais e afirmar que a prática da mimese em Luciano não se dá independentemente dos "horizontes de expectativa" de sua época e que, afinal, não teria sentido ser de outra forma. 
Jones, em Culture and Society in Lucian (Jones, 1986), avança na mesma direção que Baldwin e Peretti, embora com abordagem diversa das de ambos. Assim, descarta a existência de qualquer interesse social ou político da parte de Luciano, limitando as conexões da obra com o tempo a aspectos mais dispersos, envolvendo realidades mais pontuais e figuras isoladas. Recusa, ao mesmo tempo, de modo radical, a imagem proposta por Bompaire de Luciano "as the self-absorbed artist", em cuja poética a observação da atualidade "is reduced to the lowest degree possible". Para entender Luciano, declara Jones, "it is necessary to examine both his culture and his society" (Jones, 1986, p.4-5), concluindo: "When Lucian imitaded and praised the old masters, he was not encouraging his readers to turn their backs on the present, but was inviting them to join in the affirmation of a common heritage. (...) His society consisted not only of those within his acquaintance but all those Greeks and Romans who shared a love of classical literature and of Attic refinement. For him and for them culture was not something apart from the world, indiferent to the present. It was what made them a class allied in taste and feeling, a true society" (Jones, 1986, p.159). Como se vê, a intenção é situar a crítica de Luciano no nível de uma comunidade cultural, considerando-se tanto a perspectiva da produção quanto da recepção de sua obra. $O$ que se pode reparar na posição de Jones é que não inclua, nessa crítica à cultura, as questões, básicas em qualquer sociedade, envolvendo a própria estruturaçāo desta e o exercício, nela, do poder, ambos os aspectos do ponto de vista das representaçōes que fazem de qualquer sociedade uma "verdadeira sociedade".

Finalmente, resta mencionar alguns trabalhos mais recentes, que voltam a enfocar aspectos mais propriamente poéticos da produção luciânica, sem os vieses da dicotomia entre "imitação" e "criação", "tradição" e "originalidade", "criação literária" e "observação da realidade", "anacronismo" e "engajamento social". Nessa linha, deve-se citar o breve mas esclarecedor artigo de Korus, "The Theory of Humour in Lucian of Samosata" (Korus, 1984), que tenta depreender a citada teoria dos próprios textos de Luciano, definindo-a basicamente como um princípio de nāo envolvimento, a partir do qual se produz o riso. A mesma orientação está presente nos trabalhos de Hall, Lucian's Satire (Hall, 1981) e de Branham, Unruly Eloquence: Lucian and the Comedy of Traditions (Branham, 1989), o livro mais recente sobre o polêmico escritor.

Ultrapassando o debate entre mimese literária e observação da realidade, Branham concentra-se na análise dos processos poéticos: "This Book" ele afirma - "starts from the assumption that what made Lucian of interest to such varied audiences over the centuries is not his sources or contexts, whether 'traditional' or 'topical', but his modes of transforming them" (Branham, 1989, p.2). Para o estabelecimento desses princípios poéticos que, de um certo modo, tornam luciânicas todas as matérias e gêneros que Luciano toca, Branham considera as questōes da perspectiva tanto das intençōes quanto dos efeitos da obra, num processo de interação que soma o escritor e seu público. Analisando muitas vezes peças desprezadas pela maior parte dos críticos, como os chamados "prefácios", procura depreender os princípios gerais da poética luciânica a partir do que declara a esse respeito o próprio Luciano. Assim, se é certo que "Lucian's parodic experiments with established forms combine to form an unusual oeuvre, whose very heterogeneity betrays a consistent approach to the past", é também certo que existe nela "a writer's search (theoria) for voices and forms adaptable to the present" que, justamen- 
te, garante sua unidade. Nesse contexto, "the humor is not instrumental, a way of reinforcing a point or evoking a point of view, but also symptomatic of a literary method" (Branham, 1989, p.213).

Como se vê, a história da "questão luciânica"' não deixa de refletir, em ritmos variados, a própria história da crítica literária em nossa época. Do historicismo do século passado à concentração de todo interesse apenas na própria obra, dessa concentração ao esforço de situá-la de novo em seu meio, forjou-se, sucessivamente, a imagem de um escritor pouco original porque devedor de outros, original mas recluso em sua biblioteca, interessado nos grandes problemas de seu tempo ou simplesmente escrevendo para um público específico. $\mathrm{Na}$ verdade, os problemas não se resolveram. Para nossa felicidade, o mundo (como as grandes obras) é muito mais rico e variado que consegue dizer nossa vã filosofia (e crítica literária)! Existem questões já tratadas mas ainda mal resolvidas - como a da visão que tem $\mathrm{Lu}$ ciano do Império, sua postura diante das desigualdades sociais, sua consciência a respeito de sua obra em termos das próprias intenções, dos efeitos e do público que visa. Existem outros problemas que foram pouco explorados, como a crítica de Luciano aos diferentes gêneros de discurso, o que considero um ponto essencial para definir-se o lugar do próprio lógos luciânico no contexto da literatura grega ${ }^{16}$. Enfim, resta admitir que ainda há muito que aprender sobre Luciano - e, conseqüentemente, muito ainda a dizer-se e escrever-se sobre ele, entendida sua obra sob as múltiplas facetas da produção de um autêntico pensador da cultura.

\section{Notas}

1- Sobre esse conceito de clássico, ver Saldanha, 1983; tratei também do assunto em Brandão 1992, p.45-85. Sobre a polêmica avaliação de Luciano ao longo dos séculos, afirma Branham: "I know of no classical author who has received such contradictory evaluations" (Branham, 1989, p.212).

2- Há vários exemplos de edições nesse feitio. Cito apenas, da série "Les classiques pour tous", da Libraire Hatier, o volume preparado por $\mathrm{H}$. Berthaut, contendo o diálogo $\mathrm{O}$ sonho ou $\mathrm{o}$ galo, em que se mutila o texto em 32 .

3- A dúvida fica por conta de Asno, uma vez que pode ser que o texto que possuímos, integrante do corpus lucianeum, não seja de Luciano, tendo-se perdido a sua versão da mesma história (ver Perry, 1967, p.211-235). Embora eu próprio não acredite nas razōes apontadas para negar que o Asno que conhecemos não seja de Luciano.

4- Sobre o assunto, existe o livro de Robinson (Robinson, 1979), embora trate apenas dos casos de influência direta.

5- Abordei esse problema de modo pontual com relação à história da medicina em Brandão, 1990.

6- Cf. ainda contemporaneámente declara Reardon: "Lucian knows all the answers; and they are all 'No'" (Reardon, 1965, p.XXIX).

7- Cito a segunda edição do livro de Bakhtin, revista, e aumentada. A primeira edição é de 1929. É evidente que sua abordagem da sátira menipéia depende de Helm.

8- Sobre Filostrato, ver Anderson, 1986; também meu trabalho já citado (Brandão, 1992, p.91-105).

9- "Loukiands dè ho ek Samosáton, anèr spoudaîos es tò gelasthênai, Demónaktos philosóphou kat'ekeínous toùs khrónous bion anégrapsen, én ekeînoi te tôi biblioi kai állois elakhistois di'hólou spoudásas." (Eunapius, VS, 454).

10- "Lucianus, quid diis et hominibus non pepercit." (Lactantius, Inst. div. I, 9).

11- "Parà tôn Kynikôn, hôn heîs ên kaì Loukianós, ho toùs dialógous katà pánton homoû skhedòn tôn te eireménon, 
tôn te paraleleiménon, syntázas." (Isidoro, Epistulae IV, 55).

12- Helm afirmava, em 1902: "Dass Lucian niemals ein Philosoph war, ist heute bekannt" (Helm, 1902, p.188). Não se trata, entretanto, de ponto pacífico, em nenhuma das fases históricas da crítica luciânica. Consideram Luciano filósofo, Iacob ac Legnano e N. Zoppino, no século XVI; G. Boselli, no século XVII; em nosso século; A.M. Jacquin, que detecta nele preferência pelo epicurismo; A. Rivaud, que o qualifica como cético; Terzaghi, que o faz cínico; Zeller, eclético; Rohde, epicúreo (apud Quacquarelli, 1956, p.21). Highet define Luciano como "philosophical satirist" (Highet, 1951, p.304). Quacquarelli acredita que, no Nigrino, Luciano relata uma conversão sincera e histórica ao platonismo (Quacquarelli, 1956, p.49). Mais recentemente, Joly retomou a tese de que Luciano é filósofo, dependendo a possibilidade de tal classificação apenas do que se considera como filosofia (Joly, 1981). Discuti essas questões em meu trabalho já citado (Brandão, 1992).

13- "L'Essai sur la vie et les oeuvres de Lucien, 1882, de M. Croiset, d'ailleurs admirable d'élégance et de finesse, montre un grand dédain pour le problème de l'imitation, et expose une conception purement formelle de l'originalité dominant les emprunts..." (Bompaire, 1958, p.8, n.1).

14- Basta lembrar o artigo de van Groningen, texto de conferência proferida em congresso da FIEC, nos anos 60 , que deprecia a literatura do segundo século como decadentista, considerando principalmente sua falta de "originalidade" e lembrando, a favor disso, inclusive, a raridade da poesia naquela época, um gênero, por natureza, segundo o mesmo autor, superior porque mais "original" que a prosa (cf. Groningen, 1965).

15- Observa Relihan que a abordagem de Anderson dos métodos de composição e uso de motivos por Luciano "runs the risk of reducing the study of Lucian to a contemplation (and sometimes a rather joyless contemplation) of a secondrate artist's notion of art for art's sake, and would ask us to see as the only content in Lucian the erection of a literary façade and the clever adoption of pretenses and poses" (Relihan, 1987, p.185).

16- Da questão do tópos do lógos luciânico no contexto dos gêneros de discurso tradicionais, tratei em A poética do hipocentauro (Brandão, 1992, p.137-333).

\section{Referências Bibliográficas}

ALLINSON, F.G. Lucian Satyrist and Artist. Boston: 1926.

ANDERSON, G. Lucian's Classics: Some Short Cuts to Culture. Bulletin of the Institut of Classical Studies of the University of London, n.23, p.59-68, 1976(a).

ANDERSON, G. Lucian: a Sophist's Sophist. Yale Classical Studies. New Haven, v.XXVII, p.61-92, 1982.

ANDERSON, G. Lucian: Theme and Variation in the Second Sophistic. Leiden: Mnemosyne (supp.41), 1976(b).

ANDERSON, G. Studies in Lucian's Comic Fiction. Leiden: Mnemosyne (supp.43), 1976(c).

ANDERSON, G. Philostratus: Biography and Belles Lettres in the Third Century A.D. London: Croom Helm, 1986.

BALDWIN, B. Lucian as Social Satirist. The Classical Quartely. Oxford, v.XI, n.2, p.199-208, 1961.

BALDWIN, B. Studies in Lucian. Toronto: Hakkert, 1973.

BAKHTIN, M. Problemi poetiki Dostoievskovo. Moscovo: 1963.

BOMPAIRE, M.J. Lucien écrivain. Imitation et création. Paris: Boccard, 1958.

BRANDĀO, J.L. Doentes, doenças, médicos e medicina na obra de Luciano de Samósata. Cadernos de 
História e Filosofia da Ciência. Campinas, v.2, n.2, p.1-20, 1990. BRANDÄO, J.L. $A$ poética do hipocentauro; identidade e diferença na obra de Luciano de Samósata. São Paulo: 1992 (tese).

BRANHAM, R.B. Unnuly Eloquence: Lucian and the Comedy of Traditions. Cambridge: Harvard Univ., 1989.

CASTER, M. Études sur Alexandre ou le faux prophète de Lucien. Paris: 1938.

CASTER, M. Lucien et la pensée religieuse de son temps. Paris: Belles Lettres, 1937.

COENEN, J. (ed) Lukian, Zeus tragodos. Meisenheim am Glan: A. Hain, 1977.

CROISET, M. Essai sur la vie et les oeuvres de Lucien. Paris: 1882.

CROISET, A. \& CROISET, M. Histoire de la littérature grecque. Tome 5. Paris: A. Fontemoig, 1899.

GALLAVOTTI, C. Luciano nella sua evoluzione artistica e spirituale. Lanciano: G. Carabba, 1932.

GRONINGEN, B.A.v. General Literary Tendencies in the Second Century A.D. Mnemosyne. Leiden, n.18, p.41-56, 1965.

HALL, J.A. Lucian's Satire. New York: 1981.

HELM, R. Lucian und die philosophenschule. Neue Jahrbücher für das Klassische Altertum, n.9, p.188-213; 351-369, 1902.

HELM, R. Lukian und Menipp. Leipzig: Teubner, 1906.

HIGHET, G. The Classical Tradition. Oxford: Clarendon, 1951.

HIME, H.W.L. Lucian, the Syrian Satirist. London: Spottiswoode, 1900.

HOUSEHOLDER, F.W. Literary Quotation and Allusion in Lucian. Columbia: King's Crown, 1941.

JOLY, R. La réfutation des analogies dans l'Hermotime de Lucien. L'Antiquité classique. Louvain-la-
Neuve, v.L, n.1-2, p.417-426, 1981.

JONES, C.P. Culture and Society in Lucian. Cambridge: Harvard, 1986.

KORUS, $K$. The Theory of Humour in Lucian of Samosata. Eos. Wroclaw, n.72, p.295-313, 1984.

MCCARTHY, B.P. Lucian and Menippus. Yale Classical Studies. New Haven, v.4, p.3-55, 1934.

OLIVER, J.H. The Actuality of Lucian's Assembly of the Gods. American Journal of Philology. Baltimore, n.101, p.304-313, 1980.

PERETTI, A: Luciano: un intellettuale greco contro Roma. Firenze: La Nuova Vita, 1946.

QUACQUARELLI, A. La retorica antica al bivio. Roma: s/ed., 1956.

PERRY, B.E. The Ancient Romances. Berkeley-Los Angeles: Univ. of California, 1967.

REARDON, B.P. Courants littéraires grecs des IIe. et IIIe. siècles après J.C. Paris: Belles Lettres, 1971.

REARDON, B.P. (ed.) Lucian, Selected Works. Indianapolis-New York: Liberal Arts, 1965.

RELIHAN, J.C. Vainglorious Menippus in Lucian's Dialogues of the Dead. Illinois Classical Studies. Urbana, v.XII, n.1, p.185-206, 1987.

ROBINSON, C. Lucian and his Influence in Europe. Bristol: Duckworth, 1979.

SALDANHA, N. Os "clássicos" e a exemplaridade histórica. Humanidades. Univ. de Brasília, v.I, n.3, p.28-36, 1983.

SCHWARTZ, J. Biographie de Lucien de Samosate. Bruxelles: Latomus, 1965.

SCHWARTZ, J. La "conversion" de Lucien de Samosate. L'Antiquité classique. Louvain-la-Neuve, n.33, p.384-390,1964. 